\title{
Spatial temperature profiling by semi-passive RFID loggers for perishable food transportation
}

\author{
Reiner Jedermann , Luis Ruiz-Garcia , Walter Lang \\ Microsystems Center Bremen (MCB), University of Bremen, Otto Hahn Allee NW1 - D-28359 Bremen, Germany \\ Laboratorio de Propiedades Físicas y Tecnologías Avanzadas en Agroalimentación (LPF-TAG), Universidad Politécnica de Madrid, \\ E.TS.I. Agrónomos, Avda. Compiutense s/n 28040 Madrid, Spain
}

Keywords:

Semi-passive RFID

Temperature monitoring

Food transportation

\begin{abstract}
A B S T R A G T
Perishable food products are at risk of suffering various damages along the cold chain. The parties involved should control and monitor the conditions of goods in order to ensure their quality for consumers and to comply with all legal requirements. Among environmental parameters during transport, temperature is the most important in prolonging the shelf life of the products. Radio Frequency IDentification (RFID) is an emergent technology that has proven its suitability for tracking and tracing in logistics. This paper shows how miniaturized RFID temperature loggers can be adapted to analyze the amount of local deviations, detect temperature gradients, and estimate the minimum number of sensors that are necessary for reliable monitoning inside a truck or container. These devices are useful tools for improving the control during the transport chain and detecting weaknesses by identifying specific problem areas where corrective actions are necessitated. In a first step, the RFID tags were tested by studying the temperature distribution in a pallet. Then, 15 shipments from a wholesale company in Germany in compartmented trucks were monitored, covering different temperature range conditions. During transport, several temperature differences were found in the same compartment. Using a factorial Analysis of Variance (ANOVA) the influence of different factors has been studied, such as: the location of the logger, type of truck, and external temperature. The shelf life, or keeping quality model, was applied to the recorded temperature profiles. Suggestions for future research areas are also discussed.
\end{abstract}

\section{Introduction}

The internal biological and chemical processes of fresh produce continue after harvesting. Produce is a living, breathing commodity, which emits heat and carbon dioxide. The risk of a failure in the cold chain could cause excessive ripening, weight loss, softening, color and texture changes, physical degradation and bruising, and attack by rot and molds. These factors affect freshness, desirability, and marketability. Therefore, temperature is the most important factor when prolonging the practical shelf life of produce. The aim of the freight owner is to ensure that the product is delivered to the end user in an excellent and fresh condition, enhancing the reputations of producers and suppliers as integral parts of the whole transaction. The main interest of the transport operator is in knowing whether the condition of a delivered item is satisfactory or needs additional examination because of an emergent risk of contamination or unwanted ripening.

Radio Frequency Identification (RFID) is an emergent technology that is being used increasingly in many applications. 
RFD has been successfully applied to logistics and supply chain management processes because of its ability to identify, categorize, and manage the flow of goods and information throughout the supply chain (Jansen and Krabs, 1999; Jones et al., 2004; Angeles, 2005; Twist, 2005; Attaran, 2007; Ngai and Riggins, 2008). However, the supply chain management of fresh foods requires fast decisions because goods are forwarded within hours after arrival at the distribution center. The quality of fresh meat, fish, or agnicultural products might change rapidly. Appropriate planning calls for more information than that which could be provided by standard RFID tracking and tracing.

RFID semi-passive hardware outfitted with sensors can extend the range of application beyond the areas mentioned, because such hardware provides new features such as temperature and shock measurement. This hardware represents a new type of wireless sensor that can be very useful for cold chain monitoring. Among environmental parameters during transport, temperature has the most significant influence on the quality of food products. Strong coordination and cooperation of all involved parties are necessary. It is fundamental to minimize cold chain delays during harvest as well as at the packing center, carrier's depot, container-packing depot, or container terminal. In addition, it is essential to ensure that temperatures inside the transport units are correct; local temperature deviations can occur in almost any transport situation. Reports from literature indicate that deviations of $5^{\circ} \mathrm{C}$ or more occur. There is broad variance in the rate of temperature changes, depending on the transport conditions (Tanner and Amos, 2003a,b; Moureh and Flick, 2004; Wild et al., 2005; Punt and Huysamer, 2005; Rodríguez-Bermejo et al., 2007). McMeekin et al. (2006) used active sensors to record spatial temperature profiles. Gras (2006) used passive RFID loggers to test the probability to find a certain temperature in a transport, but did not go into spatial deviations.

Studying and analyzing temperature gradients inside refrigeration rooms, containers, and trucks is a primary concern of the industry. Refrigeration inhibits the growth of decay-producing microorganisms and restricts enzymatic and respiratory activities during the postharvest period, decreases water loss by providing a humid environment, reduces ethylene production, and decreases the sensitivity of products to ethylene.

Unfortunately, no unique scale exists to assess the effects of temperature abuse. Most companies perform only a minimum level of temperature control in order to comply with food regulations. These regulations mainly concern fixed temperature thresholds, but do not give any information about the effects of temperature deviations that are slightly below the threshold. For optimization of supply chain processes and increasing consumer acceptance, a more refined scale of quality assessment is necessary. In addition to a printed expiration date, a dynamic quality index should be recalculated if temperature conditions change.

Improved cool chain management methods such as the 'Quality oriented tracking and tracing systems' (QTT) (Scheer, 2006) offer new features. An example of this approach is the 'Safety Monitoring and Assurance System' (SMAS) that was developed to reduce customers' risk of consuming microbiologically contaminated meat (Koutsoumanis et al., 2005). The growth rate of pathogens was estimated based on temperature history. At a control point the package was either sent to the local or the export market. A case study of cooked ham was carried out based on previous surveys of distribution chain conditions. Following the SMAS approach, the number of products with zero shelf life could be reduced from $12 \%$ to $4 \%$ in the export store compared to normal FIFO ('First in first out') handling.

Quality problems should be detected as quickly as possible, and alarms should be triggered when temperature gradients cross a threshold. Even if direct access to the means of transport is not possible, online notifications offer new opportunities for improved transport planning. Emergent technologies such as Wireless Sensor Networks (WSN) and RFID are expected to play important roles (Wang et al., 2006).

The use of wireless sensors in refrigerated vehicles was proposed by Qingshan et al. (2004). The vehicles could host a variety of sensors to detect, identify, $\log$, and communicate what happens during the journey, monitoring the status of perishable products in transport. Jedermann et al. (2006) and Behrens et al. (2006) presented a system for intelligent containers that combined wireless sensor networks and RFID. Ruiz-Garcia et al. (2007) studied and analyzed intermodal refrigerated fruit transport that integrated wireless sensor networks with multiplexed communications, fleet management systems, and mobile networks. Also the performance of ZigBee-based wireless sensor nodes for real-time monitoring of fruit logistics has been studied (Ruiz-Garcia et al., 2008).

The warehouse operator could then know not only the location of the goods, but also their current states. In an advanced solution, the operator would know how to handle the incoming freight before the truck or container arrived. In fact, there would be no real need to transmit full temperature charts of individual freight items. Automated quality assessment systems could free the transport operator from the task of manually analyzing temperature charts. If the system were implemented on a locally embedded platform close to the sensor itself, it could greatly reduce the amount of communication data and costs. Only alarm notifications or state flags would need to be transferred over mobile networks. These solutions are differentiated primarily by the location of temperature data processing.

\section{Objectives}

The main objective of this paper is to study and identify the most suitable implementation for the monitoring of refrigerated transport of perishable goods by means of RFD, in order to analyze the transport chain and detect weaknesses. Further goals include detecting the amount of local deviations and estimating the minimum number of sensors necessary for reliable temperature control inside a truck or container. 


\section{Materials and methods}

\subsection{RFID semi-passive tags}

RFID systems are comprised of three main components: the tag or transponder, the reader or transceiver that reads and writes data to a transponder, and the computer containing database and information management software (Suhong et al., 2006).

RFID tags can be active, passive, or semi-passive. Passive and semi-passive RFID send their data by reflection or modulation of the electromagnetic field that was emitted by the Reader. The typical reading range is between $10 \mathrm{~cm}$ and $3 \mathrm{~m}$. The battery of semi-passive RFID is only used to power the sensor and recording logic

The communication of active RFD is powered by his own battery. This enables higher signal strength and extended communication range of up to $100 \mathrm{~m}$. But the implementation of active communication requires larger batteries and more electronic components. The typical price of active sensors is between five or ten times the price of semi-passive RFID loggers.

In this paper we focused on analyses of the performance of semi-passive RFID loggers in order to enable an economical solution for the spatial profiling of transports with a high number of loggers.

A third miniaturized data logger with electrical interface was included in our research as reference (Angeles, 2005).

Data loggers are standard tools for the supervision of $\mathrm{cool}$ chains. New developments in the recent years have provided miniaturized solutions for temperature monitoring. Interfaces for data readout have shifted from electrical types to those that employ infrared and wireless RFID communication. Three types of miniaturized data loggers were compared in laboratory experiments and field tests. The iButton loggers from Dallas Semiconductor/Maxim (wwwibutton.com) have the size of a button cell and contain a 1-Wire electrical interface. These loggers offer a large storage capacity, capable of holding up to 8000 measurement points. The Variosens RFD chip from KSW Microtec (www.ksw-microtec.com), available since the middle of 2006 , can measure and store 700 temperature points. The Turbotag data loggers (www.turbo-tag.com) use the same chip, but undergo an extended calibration process.

The major drawback of this technology is the limited reading range of about $20 \mathrm{~cm}$, comparable to other $13.56 \mathrm{MHz}$ passive RFD tags (ISO15693). Sensor tags with UHF interfaces are under research by some manufacturers such as the Italian Company CAEN S.p.A (http:/www.caen.it/rfid/syproduct.php?fam=tags\&mod=A927). These tags will extend the reading range to a few meters and allow for automated readout during the unloading of the transport, but their signals cannot penetrate metals or liquids. Accessing passive tags during transport in a packed container is far beyond technical feasibility.

The accuracy of data loggers is a critical issue in cold chain management. This accuracy becomes even more important if the objective is early detection of temperature changes and gradients. Standards for food distribution allow deviations of $\pm 0.5^{\circ} \mathrm{C}$ from the set point (BS EN 12830,1999 ).

\subsection{Study design}

In a first step, different RFID loggers were compared in order to find the most appropriated one for monitoring cold chain logistics. Several tests were carried out in a climatic chamber.

In separate experiments with 20-40 samples per logger type, the temperature in the chamber was increased stepwise. The sampling rate of the loggers was set to $5 \mathrm{~min}$. Constant temperatures of $-10^{\circ} \mathrm{C}, 0^{\circ} \mathrm{C}, 15^{\circ} \mathrm{C}$ and $30^{\circ} \mathrm{C}$ were maintained over a time span of at least of $30 \mathrm{~min}$, giving a minimum of 7 valid samples per logger and temperature step. Field tests covered two different conditions. In the first setting, the temperature distribution inside a packed and sealed pallet was considered. For evaluation of the penetration depth of temperature changes, two test pallets were equipped with 50 or $70 \mathrm{KSW}$ Variosens data loggers.

The tags were placed in pre-cooled boxes of dairy products. 180 boxes were loaded in 5 layers onto a pallet of $80 \mathrm{~cm} \times 120 \mathrm{~cm}$ to a height of $95 \mathrm{~cm}$. The tagged boxes were placed in the bottom, middle and top layers. After 1 day at the optimal temperature of $6.5^{\circ} \mathrm{C}$ the pallet was moved to a nonrefrigerated storage space with a temperature of about $20^{\circ} \mathrm{C}$. Because of the lack of air ventilation, the surface of the pallet warmed up to only $16.5^{\circ} \mathrm{C}$. After 3 days the pallet was moved back to the refrigerated room. A German food manufacturer and distributor provided the data.

In contrast to the first setting with an even distribution of thermal mass over space, in the second setting the spatial temperature distribution inside delivery trucks with partially filled boxes were considered. The experiments were carried out at Rungis Express, Germany, a trading company dealing in luxury and exclusive foods.

Rungis Express customer deliveries are transported by trucks, which are separated into three compartments with different temperatures zones for deep-frozen goods, fish and meat, and vegetables. Each compartment is equipped with separate ventilation/vaporizer units.

The inner dimensions of the insulated box were $2.48 \mathrm{~m}$ width $\times 2.35 \mathrm{~m}$ height with a total length of $6.05 \mathrm{~m}$. The length of the compartments could be adjusted by movable room dividers. In a typical delivery, the deep freezer zone at a set point of $-29^{\circ} \mathrm{C}$ on the side of the driver cabin had a length of $1 \mathrm{~m}$. The length of the middle compartment with a set point of $0^{\circ} \mathrm{C}$ was adjusted to $2.9 \mathrm{~m}$. The remaining length for the vegetable compartment on the door side was $1.9 \mathrm{~m}$. A central Thermo King Spectrum refrigeration unit mounted above the driver cabin supplied the vaporizer units for the three compartments.

The middle compartments of two different trucks were each equipped with 40 data loggers. The positions of the loggers are depicted in Fig. 1. Two additional loggers were placed between the driver cabin and box of each truck in order to measure the ambient temperature. The experiment was repeated eight times, resulting in 16 monitored shipments.

\subsection{Data analysis}

Several analyses of variance (ANOVA) were performed, selecting the data of each experiment in order to study the effect of some independent variables (factors) on one dependent vari- 


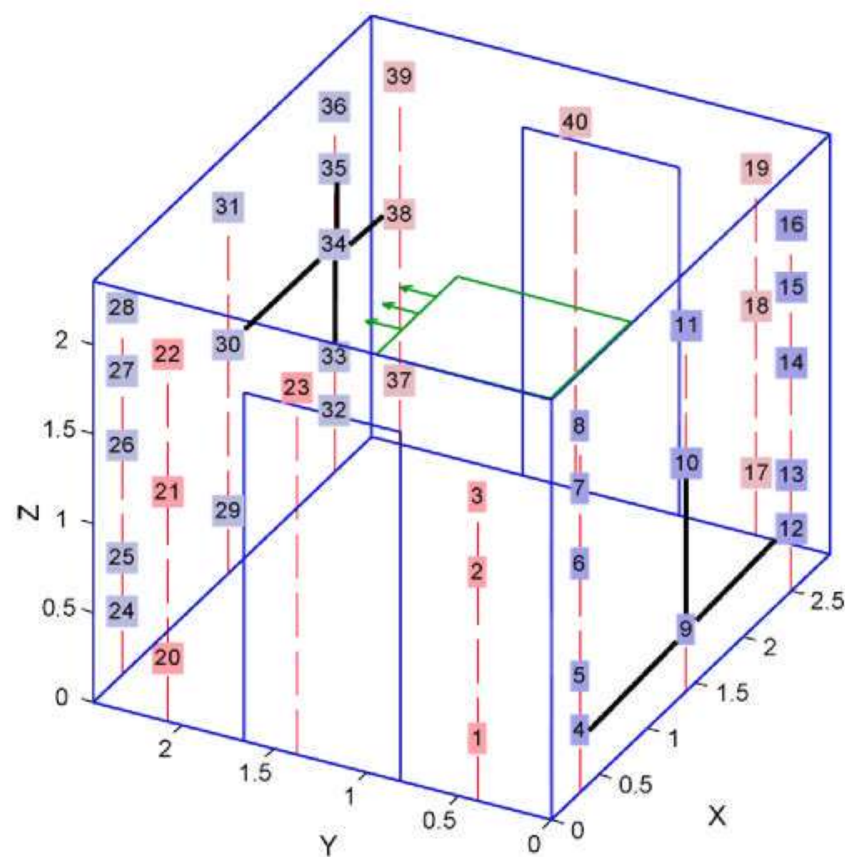

Fig. 1 - Positions of the data loggers and the refrigeration unit under the ceiling (green). (For interpretation of the references to color in this figure legend, the reader is referred to the web version of the article.)

able (inside temperature) (Devore and Farnum, 2004). The data obtained include five different factors affecting temperature measurements inside the transport: location of the RFID loggers (X-position, Y-position and Z-position), truck type, and ambient temperature (T-outside). For the statistical analyses a program was developed using dedicated Matlab code.

Due to the significant variation of the conditions from one experiment to another, the analyses makes use of a normalized temperature difference $\left(\Delta T_{n i j}\right)$, which is computed with respect to the set point and to the outside temperatures (see Eq. (1)). This value gives a normalized measure with respect to the varying ambient conditions of the experiments in order to judge the difference between them (Rodríguez-Bermejo et al., 2007)

$\Delta T_{n i j}=\frac{\overline{T_{i j}}-T_{s i}}{\overline{T_{a i}}-T_{s i}} \quad\left(\right.$ with $\left.-1<\Delta n_{i j}<1\right)$

$\Delta T_{n i j}=$ Normalized temperature difference for experiment $i$ and logger $j ; T_{i j}=$ Temperature for experiment $i$ and logger $j$ $\left({ }^{\circ} \mathrm{C}\right) ; \mathrm{T}_{\mathrm{si}}=$ Set point $\left({ }^{\circ} \mathrm{C}\right) ; \mathrm{T}_{\mathrm{ai}}=$ Ambient temperature $\left({ }^{\circ} \mathrm{C}\right)$.

One statistical parameter that provided interesting information is the variance of $\Delta T_{n i j}$. If this value is more than one that means temperature has fluctuated more inside the transport than outside.

\subsection{Shelf life model}

Different physical properties can be subsumed in the concept of 'keeping quality' or 'remaining shelf life'. The shelf life indicates the number of remaining days until a productspecific threshold will be passed. This threshold could be color loss, bacterial limit, or consumer acceptance (Tijskens and Polderdijk, 1996; Jedermann et al., 2007).

The remaining shelf life of a product is scaled to a given standard temperature. In general this value should equal the temperature in the retail store or the final destination of the product. The speed of chemical or enzymatic reactions, which lead to a decrease of quality, is calculated according to the law of Arrhenius for reaction kinetics. Vegetables that are not sensitive to 'chilling injuries' can be modeled by a single Arrhenius function. Two parameters must be estimated for the model: the initial quality or shelf life at standard temperature and the activation energy of the most crucial chemical process. Fig. 2 gives the 'loss per day' or acceleration factor of the decay processes as a function of temperature according to the model parameters listed by Tijskens and Polderdijk (1996). The left part displays the model for some vegetables that can be approximated by a first-order model. For example, lettuce with an initial shelf life of 5.6 days at a standard temperature of $5^{\circ} \mathrm{C}$ loses 2 days of shelf life per day of transport at a temperature of $10^{\circ} \mathrm{C}$.

Tropical fruits and tomatoes should be stored and transported at higher temperatures because of their sensitivity to chilling injuries. The right part of Fig. 2 shows the modeling of fruits by a second Arrhenius function with negative activation energy. The curves are scaled to a standard temperature of $15^{\circ} \mathrm{C}$. For these models the second activation energy and a weight factor must be estimated as additional parameters.

\section{Results and discussion}

\subsection{Comparison of RFID loggers}

For the test temperatures, the average and standard deviation $\delta$ (root mean square deviation) were calculated separately for the three logger types in Table 1. Part of the difference between the average temperature and the set point might have resulted from tolerances of the climatic chamber, which were specified by the manufacturer to be $0.1^{\circ} \mathrm{C}$. The percentage of measurements with a difference to the average value less than the deviation $\pm \delta$ was between $66 \%$ and $73 \%$, which was very close to the expected value for a Gaussian distribution of $2 / 3$. The iButtons produced the best results with a deviation of $\pm 0.09^{\circ} \mathrm{C}$, followed by the TurboTags with $\pm 0.19^{\circ} \mathrm{C}$, and the KSW tags with $\pm 0.36^{\circ} \mathrm{C}$.

\subsection{Temperature distribution}

The positions and temperatures of different measurement points inside the densely packed pallet of the first setting are displayed in Fig. 3. Due to the large thermal mass of the goods, the effect of changes in the ambient temperature on the temperature of the pallet core was delayed for several days. After $60 \mathrm{~h}$ the change in core temperature had only reached $50 \%$ of the change in ambient temperature.

In the next step, the time behavior of the temperature was investigated. Fig. 4 shows the output of three selected loggers with distances to the surface of $1 \mathrm{~cm}, 20 \mathrm{~cm}$, and $40 \mathrm{~cm}$, as well as the ambient temperature (shown as bold lines). Data analysis showed that the temperature of points close to the surface 

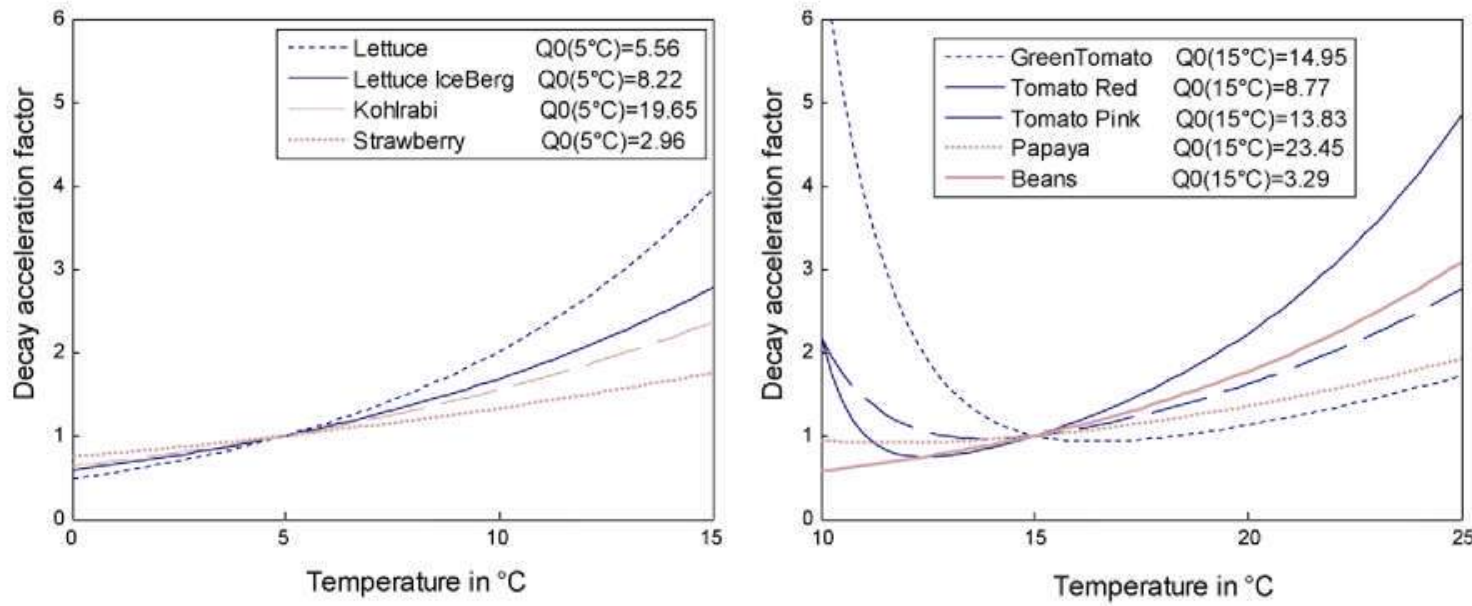

Fig. 2 - Decay of shelf life for different agricultural products. Loss per day as function of temperature for different fruits. Fruits that are sensitive towards chilling injuries can be modeled by a second Arrhenius function (right). The acceleration of decay processes by temperature deviations is given in relation to a reference temperature of $5^{\circ} \mathrm{C}$ (left) or $15^{\circ} \mathrm{C}$ (right).

Table 1 - Test of different logger type in climatic chamber

Experiment 1: KSW (23 units)

Experiment 2: Turbo-Tag (36 units)

Experiment 3: IButton (20 units)

\begin{tabular}{|c|c|c|c|c|c|}
\hline Temperature $\left({ }^{\circ} \mathrm{C}\right)$ & $\begin{array}{c}\text { Mean and standard } \\
\text { deviation }\left({ }^{\circ} \mathrm{C}\right)\end{array}$ & Temperature $\left({ }^{\circ} \mathrm{C}\right)$ & $\begin{array}{c}\text { Mean and standard } \\
\text { deviation }\left({ }^{\circ} \mathrm{C}\right)\end{array}$ & Temperature $\left({ }^{\circ} \mathrm{C}\right)$ & $\begin{array}{c}\text { Mean and standard } \\
\text { deviation }\left({ }^{\circ} \mathrm{C}\right)\end{array}$ \\
\hline-10 & $-10.00 \pm 0.41$ & -10 & $-9.81 \pm 0.25$ & -10 & $-9.90 \pm 0.15$ \\
\hline 0 & $0.13 \pm 0.32$ & 0 & $0.16 \pm 0.18$ & 0 & $0.12 \pm 0.06$ \\
\hline 15 & $15.17 \pm 0.29$ & 15 & $15.05 \pm 0.17$ & 15 & $15.02 \pm 0.06$ \\
\hline 30 & $30.23 \pm 0.42$ & 30 & $30.05 \pm 0.18$ & 30 & $29.99 \pm 0.09$ \\
\hline
\end{tabular}

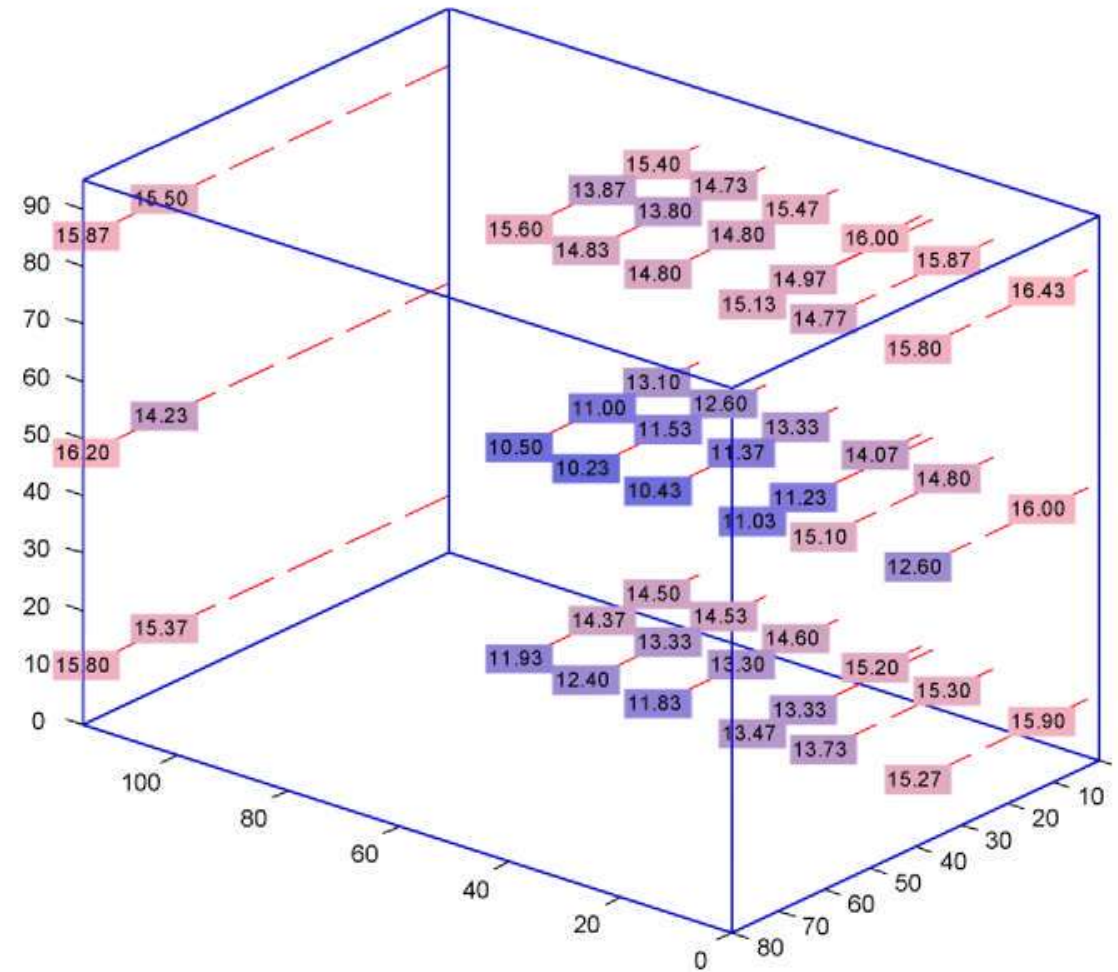

Fig. 3 - Temperature rise inside a sealed palette after $60 \mathrm{~h}$ without refrigeration. 


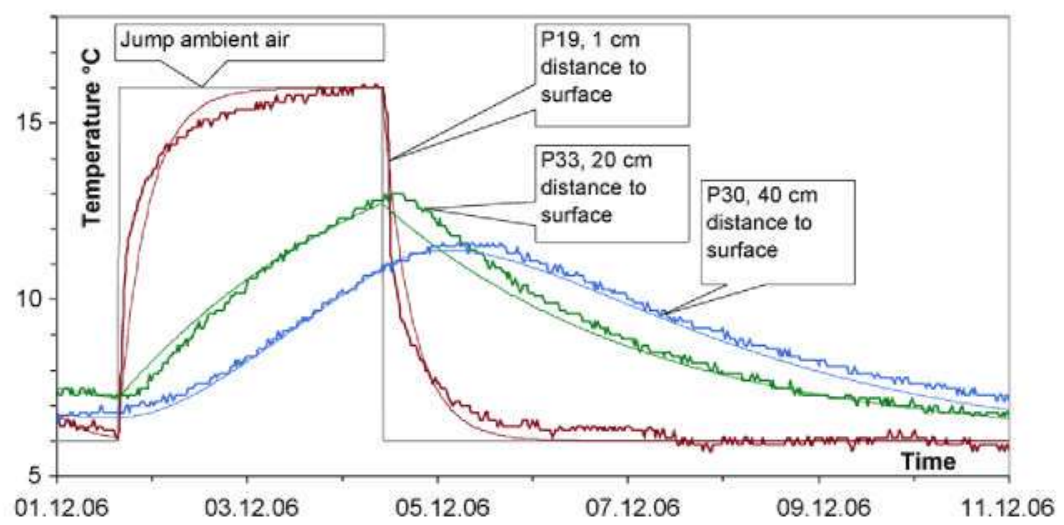

Fig. 4 - Measured (fine) and modeled (bold) temperature for three selected points inside a packed palette.

could be modeled by a first-order time-delay element with the ambient temperature as input function (shown as fine lines in Fig. 4). The delay elements were characterized by their time constants, which gave the amount of time that was passed until the internal temperature reached $63.2 \%$ of the changed input. The core temperature could be better approximated by a second-order delay. The first delay element described the transition from ambient temperature to the outer layer temperature, the second from the outer layer to the center of the pallet. Depending on the distance to surface, the time constant varied from 0.3 to 3 days. The core temperature was modeled by a serial connection of two delays with a time constant of 1.8 days each.

Table 2 refers to the results obtained from the experiments conducted in "fish and meat" mode. Mean temperature was always above the set point and in all cases deviation was more than $0.5^{\circ} \mathrm{C}$ above the recommended value. Maximum and minimum temperature data indicated considerable changes and gradients during the transport. In one case (experiment 6), the maximum temperature measured was almost $13^{\circ} \mathrm{C}$ above the set point. This peak with duration of $10 \mathrm{~min}$ affected 2 neighboring loggers.

Also in Table 2, the Mean Normalized Temperature values over zero indicate that the temperature inside the transport was higher than the set point, which is the case of majority. However, in the experiment 2 for truck two, we can see that temperature inside was under the set point. In the column of Mean Normalized Variance all values are under 1, which indicates that the fluctuations inside were less than outside.

For the second setting, Fig. 5 shows a typical time-temperature plot for some example sensor positions inside the delivery trucks. The high volume of free air and the permeability of the boxes provided good ventilation and fast reaction to temperature changes. Temperature oscillations caused by the on-off cycles of the reefer unit were found almost everywhere. The oscillations measured directly in the reefer air had amplitudes of up to $20^{\circ} \mathrm{C}$. At the walls, amplitudes between $3^{\circ} \mathrm{C}$ and $6^{\circ} \mathrm{C}$ were measured. Inside the boxes, oscillations from $1^{\circ} \mathrm{C}$ to $3^{\circ} \mathrm{C}$ were observed. Thermal delays between the reefer air and the temperature at the walls or inside the permeable boxes were almost not measurable with a sampling rate of $10 \mathrm{~min}$. All loggers reacted in less than one sampling period to changes in the air supply.
The position of the ventilation unit was identified as a major factor of influence. The average temperature of all loggers at the ventilation unit side was colder than that of the opposite side with a difference between $1.8^{\circ} \mathrm{C}$ and $2.4^{\circ} \mathrm{C}$ for the measurements taken in September and October 2006. In two experiments taken in January 2007, the difference was reduced to $1.0^{\circ} \mathrm{C}$ due to a lower ambient temperature $\left(8^{\circ} \mathrm{C}\right.$ versus $16^{\circ} \mathrm{C}$ ).

Additional experiments carried out in "deep freezer" mode showed temperature deviations of more than $10^{\circ} \mathrm{C}$. Fig. 6 gives a 3-D view of the spatial temperature distribution $1 \mathrm{~h}$ after loading frozen goods. The effects of the reefer position were overlapped by other influences, especially by differences in pre-loading temperature of the freight items.

The difference between minimum and maximum temperature measured at the walls of the truck is still present after $10 \mathrm{~h}$. The initial difference of $20^{\circ} \mathrm{C}$ (arrows in Fig. 6) was only reduced to $5^{\circ} \mathrm{C}$.

\subsection{Influence of different factors in the temperatures changes}

Five-way ANOVAs were performed, taken factors one by one, and also with combinations of factors taken two by two. The results of the ANOVAs in all cases were very similar. Considerable temperature variability inside the truck was found.

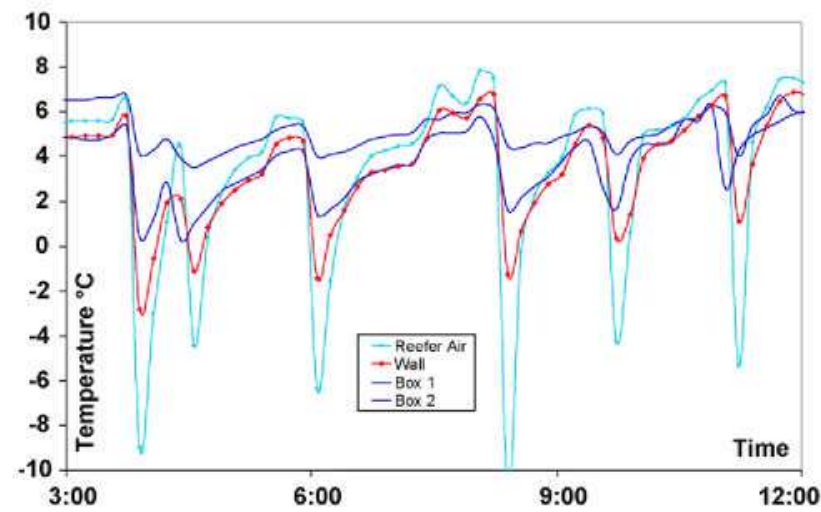

Fig. 5 - Temperature of reefer air, at walls and inside freight boxes over time. 

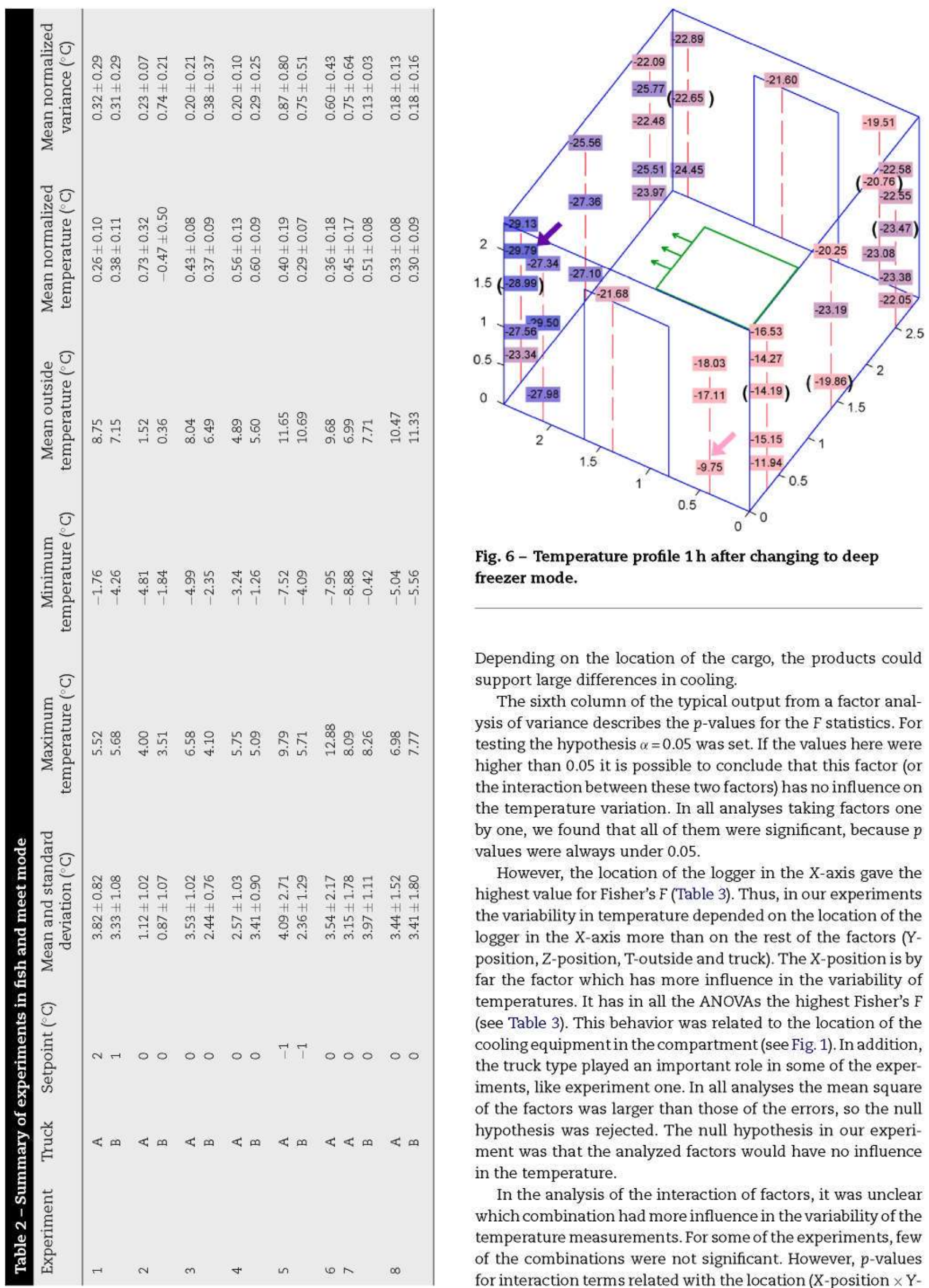

Fig. 6 - Temperature profile $1 \mathrm{~h}$ after changing to deep freezer mode.

Depending on the location of the cargo, the products could support large differences in cooling.

The sixth column of the typical output from a factor analysis of variance describes the $p$-values for the F statistics. For testing the hypothesis $\alpha=0.05$ was set. If the values here were higher than 0.05 it is possible to conclude that this factor (or the interaction between these two factors) has no influence on the temperature variation. In all analyses taking factors one by one, we found that all of them were significant, because $p$ values were always under 0.05 .

However, the location of the logger in the $\mathrm{X}$-axis gave the highest value for Fisher's $F$ (Table 3). Thus, in our experiments the variability in temperature depended on the location of the logger in the $\mathrm{X}$-axis more than on the rest of the factors ( $\mathrm{Y}$ position, Z-position, T-outside and truck). The $\mathrm{X}$-position is by far the factor which has more influence in the variability of temperatures. It has in all the ANOVAs the highest Fisher's $F$ (see Table 3). This behavior was related to the location of the cooling equipment in the compartment (see Fig. 1). In addition, the truck type played an important role in some of the experiments, like experiment one. In all analyses the mean square of the factors was larger than those of the errors, so the null hypothesis was rejected. The null hypothesis in our experiment was that the analyzed factors would have no influence in the temperature.

In the analysis of the interaction of factors, it was unclear which combination had more influence in the variability of the temperature measurements. For some of the experiments, few of the combinations were not significant. However, $p$-values for interaction terms related with the location (X-position $\times \mathrm{Y}$ - 


\begin{tabular}{|c|c|c|c|c|c|}
\hline Experiment & $X$-Position & Y-Position & Z-Position & T-outside & Truck \\
\hline 1 & 3750.30 & 31.80 & 412.95 & 57.03 & 2138.40 \\
\hline 2 & 2288.0 & 113.40 & 145.11 & 525.23 & 80.74 \\
\hline 3 & 2917.67 & 106.55 & 693.17 & 39.41 & 462.41 \\
\hline 4 & 2134.60 & 621.65 & 90.00 & 100.37 & 303.32 \\
\hline 5 & 6005.10 & 420.46 & 715.61 & 16.10 & 314.67 \\
\hline 6 & 6053.40 & 335.41 & 845.69 & 17.12 & - \\
\hline 7 & 3309.70 & 464.15 & 674.19 & 121.53 & 0.50 \\
\hline 8 & 6243.7 & 998.91 & 565.66 & 37.28 & 29.47 \\
\hline
\end{tabular}

Fishers's $F$ for the five factors considered in the experiments (confidence interval $95 \%$ ).

position, $\mathrm{X}$-position $\times \mathrm{Z}$-position and $\mathrm{Y}$-position $\times \mathrm{Z}$-position) were much lower than a typical cut-off value of 0.05 , indicating that these terms were significant.

\subsection{Number of required data loggers}

The ANOVAs showed the dependency of the measured temperature values to the $\mathrm{XYZ}$-axis, where the $\mathrm{X}$-axis has the highest impact on the temperature. But on the other hand, it is not possible to predict the value of a logger by its $\mathrm{XYZ}$-coordinates. The temperature at the logger positions is overlapped with noise and other influence factors, which have not been measured. This could be for example the loading level/stack height. These unknown influence factors make it necessary to install a high number of loggers to detect all local temperature peaks. But some of the 40 loggers in our experiments might be left out, without loosing crucial information. The recorded data were evaluated with the following method in order to estimate the minimal number of necessary loggers:

Each logger was tested against his neighbors, which are between 2 and 4 loggers in either direct vertical or horizontal line. Loggers in the comer of the neighboring wall were also counted as horizontal neighbors. The bold lines in Fig. 1 show the neighbors of logger 9 and 34 as example. The measurement in some position could be replaced by linear interpolation of the values of the neighbor sensors. But methods like inverse distance weighting or Kriging (Dutter, 1985) could not detect new local extrema. Approximation of a logger is only possible, if its temperature is within the interval of the minimum and maximum value of its neighbors. The allowed interval was extended by a tolerance level, which was set to the standard deviation of the TurboTags with $\delta=0.2^{\circ} \mathrm{C}$. Loggers at the position (i) can be left out if the temperature (T) at time (t) is inside the following interval:

$\min \left(\right.$ Neighbors $\left._{j}(t)\right)-\delta<T_{i}(t)<\max \left(\right.$ Neighbors $\left._{j}(t)\right)+\delta$

In order to reduce disturbances by the reefer peaks and to simulate the delayed reaction of the freight towards temperature changes, the measured values were low pass filtered before testing for the above condition. The time constant of the first-order delay element was set to $25 \mathrm{~min}$. The data of the deep freezer transports were tested according to this approach. The analysis of the source data of Fig. 6 gave the following results: 6 out of 40 loggers were inside the interval for the full experiment duration. 5 of them were in the middle of a vertical column and 1 in the middle of a horizontal row.
These positions are marked with brackets in Fig. 6 . Six other loggers were less than $10 \%$ of the time outside the interval. One third of the loggers might be replaced by interpolation, if the location of the cold and hot spots is known in advance. An evaluation of two other experiments in deep freezer mode showed that the number of redundant loggers is similar, but their positions change.

\subsection{Quality-oriented modeling}

Shelf life models are very useful tools for assessing the effects of temperature deviations on product quality. By taking the temperature-over-time curve as input, the model could predict the influence of short temperature peaks as well as the effect of a persistent offset from the recommended temperature. For example, an Arrhenius-type shelf life model with the parameters for lettuce (activation energy $91.58 \mathrm{~kJ} / \mathrm{mol}$, initial shelf life 5.56 days at $5^{\circ} \mathrm{C}$ ) was applied to the temperature curves of the two boxes in Fig. 1 with a difference of $1.42^{\circ} \mathrm{C}$ between their average temperatures. After the $9 \mathrm{~h}$ of express delivery the model predicted only a small variation in shelf life of 0.07 days. However, if the temperature conditions had stayed constant, the warmer box would pass the zero shelf life threshold 1.23 days earlier than the box with proper cooling (Table 4).

\subsection{Proposal of RFID implementation}

An important issue is how RFID loggers could be implemented in a normal cold chain environment.

The amount of data that can be transferred over an RFID interface during the unloading procedure is limited by two factors. First, the channel bandwidth per reader is restricted to $200 \mathrm{kHz}$ under European law to allow simultaneous operation of multiple readers in one location. Second, the time window for reads is typically no longer than one second, according to the amount of time a forklift needs to pass an RFD gate. These

Table 4-Application of the shelf life model on recorded data with parameters for lettuce

\begin{tabular}{lccc} 
Box & $\begin{array}{c}\text { Average } \\
\text { temperature }(\circ \mathrm{C})\end{array}$ & $\begin{array}{c}\text { Shelf life after } \\
9 \mathrm{~h} \text { (days) }\end{array}$ & $\begin{array}{c}\text { Zero shelf } \\
\text { life (days) }\end{array}$ \\
\hline Coldest & 3.73 & 5.24 & 6.67 \\
Warmest & 5.15 & 5.18 & 5.44 \\
\hline
\end{tabular}


restrictions make it almost impossible to read out the full temperature history of hundreds of tags during the transshipment process.

When scanning incoming goods, the first interest is determining whether the quality state of the goods is 'ok' or whether the goods need additional examination. As proposed by Emond and Nicometo (2006), this could be indicated by a light connected to a door reader at the loading platform. In their study, 'green' denoted no quality problems; the operator should put the goods to normal stock. 'Red' signified that a temperature-time threshold was overstepped, and that the operator should manually check the quality of a shipment. An intelligent RFID data logger had to process the temperature information internally and evaluate the effects on product quality. Following an inventory request by the door reader, the RFID logger answered with its identification number and a green/red state flag. Only by special request was a full temperature chart transmitted. The pre-processing of temperature data could be as simple as checking temperature threshold in order to comply with food regulations. For higher accuracy, data should include shelf life prediction and an estimation of the time-delayed core temperature by surface measurements. Passive RFD tags with the requisite embedded processing facilities are not currently available.

\section{Conclusions}

Semi-passive tags can be used to monitor environmental variables such as the temperature of chilled food refrigerated goods, to identify problem areas, and to raise alarms. RFD loggers are good tools that are available in high quantities and are cost-effective for the characterization of refrigerated transport units such as trucks or containers. However, they require manual handling because of their low reading range.

By performing ANOVA on-line, inside the transport unit, it is possible to estimate the temperature variability in the cargo and reduce the number of necessary instances of the shelf life model by grouping items with equal temperature behaviors in batches. This feature can be implemented in an intelligent container.

One problem might be that these monitoring systems create huge volumes of data that are difficult to manage, causing a huge increase in the daily volume of data in a corporate IT system. This increase impacts the hardware cost required implementing monitoring systems. Neither manual evaluation nor transmission over mobile networks is feasible due to limited bandwidth and expensive usage rates. The solution lies in implementing a decentralized data management system. Temperature data must be pre-processed close to their point of origin by intelligent systems, which could be sited at the level of RFID, sensors, or the transport unit.

The required density of the measurement network depends on the setting. For a setting with an even distribution of thermal mass and airflow, the amount of sensors might be reduced to cover the core and each surface side. But in settings like delivery trucks, one sensor per meter could be necessary for reliable detection of local temperature peaks. The first test with an unknown temperature and airflow condition should be carried out with a high number of loggers. The approach that was presented can be applied to decide whether a part of the loggers can be left out for further experiments.

Implementing a combination of RFID loggers with wireless sensor nodes further reductions in total system costs are possible. RFID data loggers can replace part of the sensor nodes. A reduced number of wireless sensors are mounted on the walls to capture the ambient temperature. These sensors are always accessible. In general, since the air or surface temperature differs from the core temperature, ambient sensors can only provide a raw estimation of shelf life, but this information will be sufficient to trigger online alarms during transport.

To improve model accuracy, additional factors such as humidity and harvest conditions must be considered. In a more complex scenario, trucks could be redirected on the basis of differences in shelf life predictions.

\section{Acknowledgments}

This research was supported by the German Research Foundation (DFG) as part of the Collaborative Research Centre 637 "Autonomous Cooperating Logistic Processes".

The measurements at partner companies were funded by the Research Cluster for Dynamics in Logistics, Bremen. We especially thank the CCG Cool Chain Group Holding AG and their daughters CCG FRA and Rungis Express AG for provision of test facilities. Furthermore we thank Sealed Air Corporation for provision of the TurboTag data loggers

\section{REFERENGES}

Angeles, R., 2005. RFID technologies: supply-chain applications and implementation issues. Information Systems Management 22 (1), 51-65

Attaran, M., 2007. RFID: an enabler of supply chain operations. Supply Chain Management: An International Joumal 12 (4), 2007.

Behrens, C., Becker, M., Gehrke, J.D., Peters, D., Laur, R., 2006 Wireless sensor networks as Enabler for Cooperating Logistics Processes. In: ACM Workshop on Real-World Wireless Sensor Networks (REALWSN'06). ACM, NY, USA, pP. 85-86.

BS EN 12830, 1999. Temperature Recorders for the Transport, Storage and Distribution of Chilled, Frozen, Deep-frozen/Quick-frozen Food and Ice cream.

Devore, J.L., Farnum, N.R., 2004. Applied Statistics for Engineers and Scientists. Duxbury Press, ISBN-10: 0534467199. ISBN-13: 978-0534467197.

Dutter, R., 1985. Mathematische Methoden in der Technik, Bd. 2 : Geostatistik. B.G. Teubner Verlag, Stuttgart.

Emond, J.P., Nicometo, M., 2006. Shelf-life Prediction and FEFO Inventory Management with RFID. Cool Chain Association Workshop 13th-14th Nov. 2006, Knivsta, Sweden: Temperature Measurements - When, Where and How? http://www.coolchain.org/events/ws2006cca.php.

Gras, D., 2006. RFID based monitoring of the coldchain. In: Kreyenschmidt, J., Petersen, B. (Eds.), cold Chain-Management, Proceedings of the 2nd international Workshop Cold Chain Management. University Bonn, May $8-9,2006$, pp. 81-82.

Jansen, R., Krabs, A., 1999. Automatic identification in packing radio frequency identification in multi-way system. Packing Technology and Science 12, 229-234.

Jedermann, R., Schouten, R., Sklorz, A., Lang, W., Van Kooten, O., 2006. Linking keeping quality models and sensor systems to 
an autonomous transport supervision system. In:

Kreyenschmidt, J., Petersen, B. (Eds.), Cold

Chain-Management, Proceedings of the 2 nd international Workshop Cold Chain Management. University Bonn, May 8-9, 2006, pp. 3-18.

Jedermann, R., Behrens, C., Laur, R., Lang, W., 2007. Intelligent containers and sensor networks: approaches to apply autonomous cooperation on systems with limited resources. In: Hü]smann, M., Windt, K. (Eds.), Understanding Autonomous Cooperation \& Control in Logistics - The Impact on Management, Information and Communication and Material Flow. Springer, Berlin.

Jones, P., Clarke-Hill, C., Shears, P., Comfort, D., Hillier, D., 2004. Radio frequency identification in the UK: opportunities and challenges. Intemational Journal of Retail \& Distribution Management 32 (3), 164-171.

Koutsoumanis, K., Taoukis, P.S., Nychas, G.J.E., 2005. Development of a safety monitoring and assurance system for chilled food products. Intemational Journal of Food Microbiology 100 (1-3), 253-260.

McMeekin, T., Smale, N., Jenson, l., Tanner, D., 2006. Microbial growth models and temperature monitoring technologies. In: Kreyenschmidt, J., Petersen, B. (Eds.), Cold Chain-Management, Proceedings of the 2nd international Workshop Cold Chain Management. University Bonn, May $8-9,2006$, pp. $71-78$.

Moureh, J., Flick, D., 2004. Airflow pattem and temperature distribution in a typical refrigerated Truck configuration loaded with pallets. International Journal of Refrigeration Bd. 27 (5), 464-474.

Ngai, E., Riggins, F., 2008. RFID: Technology, applications, and impact on business operations. International Journal of Production Economics 112 (2), 507-509.

Punt, H., Huysamer, M., 2005. Supply chain technology and assessment-temperature variances in a $12 \mathrm{~m}$ integral reefer container carrying plums under a dual temperature shipping regime. Acta Horticulturae 687, 289-296.

Qingshan, S., Ying, L., Gareth, D., Brown, D., 2004. Wireless intelligent sensor networks for refrigerated vehicle. In: IEEE 6th Symp, on Emerging Technologies: Mobile and Wireless Communication, Shangai, China.

Rodríguez-Bermejo, J., Barreiro, P., Robla, J.I., Ruiz-Garcia, L., May, 2007. Thermal study of a transport container. Journal of Food Engineering 80 (2), 517-527.

Ruiz-Garcia, L., Barreiro, P., Rodríguez-Bermejo, J., Robla, J.I., June, 2007. Monitoring intermodal refrigerated fruit transport using sensor networks: a review. Spanish journal of Agricultural Research 5 (2), 2007.

Ruiz-Garcia, L., Barreiro, P., Robla, J.L., 2008. Performance of ZigBee-based wireless sensor nodes for real-time monitoring of fruit logistics. Journal of Food Engineering 87 (3), 405-415.

Scheer, F.P., 2006. Optimising supply chains using traceability systems. In: Smith, I., Furness, A. (Eds.), Improving Traceability in Food Processing and Distribution. Woodhead Publishing Limited, Cambridge, England, pp. 52-64.

Suhong, L., Visich, J.K., Basheer, M., Khumawala, M., Chen, Z., 2006. Radio frequency identification technology: applications, technical challenges and strategies. Sensor Review 26 (3) (literature review).

Tanner, D.J., Amos, N.D., 2003a. Heat and mass transfer temperature vanability during shipment of fresh produce. Acta Horticulturae 599, 193-204.

Tanner, D., Amos, N.D., 2003b. Modelling Product Quality Changes as a Result of Temperature Variability in Shipping Systems. International Congress of Refrigeration, Washington, DC.

Tijskens, L.M.M., Polderdijk, J.J., August 1996. A generic model for keeping quality of vegetable produce during storage and distribution. Agricultural Systems 51 (4), 431-452.

Twist, D.C., 2005. The impact of radio frequency identification on supply chain facilities. Joumal of Facilities Management 3 (3), 226-239.

Wang, N., Zhang, N., Wang, M., 2006. Wireless sensors in agriculture and food industry-recent development and future perspective. Computer and Electronics in Agriculture 50, 1-14.

Wild, Y., Scharnow, R., Rühmann, M., 2005. Container Handbook, vol. 3, Gesamtverband der Deutschen Versicherungswirtschaft e.V. (GDV), Berlin. 